\title{
sciendo
}

DOI 10.2478/sbe-2019-0045

SBE no. 14(3) 2019

\section{PRODUCTIVE EMPLOYMENT AND WORKING CONDITIONS AS DETERMINANTS OF SUSTAINABLE ECONOMIC DEVELOPMENT IN SERBIA}

\author{
ĐOKIĆ MILICA \\ Faculty of Economics, University of Niš, Serbia \\ JOVANOVIĆ MILICA \\ Faculty of Economics, University of Niš, Serbia
}

\begin{abstract}
:
For decades, the concept of sustainability has been recognized as the basis for survival and further development of humanity. As the result of joint efforts, The 2030 Agenda for Sustainable Development was adopted in 2015 by United Nations member states, as a plan and direction for future prosperity. It identified 17 goals, with one of them highlighting the sustainable economic growth, productive employment and decent work. Providing quality jobs and safe working environment, while decreasing in-work poverty, are important preconditions for sustainable economic development. The purpose of this paper is to point out the importance of productive employment from the aspect of sustainable development on the example of Serbia, comparing indicators with surrounding countries and leading EU members. Particular emphasis will be placed on the main difficulties young people in Serbia deal with at the labor market, on certain inequalities and necessary strategies to alleviate the current problems. The issue of youth not in employment, education or training will be analyzed as well, along with unemployment and decent work opportunities in terms of gender and age structure. Furthermore, it aims to address the main causes of these disparities in order to indicate the changes that need to be made and suggest strategies for their implementation.
\end{abstract}

Key words: productive employment, decent work, unemployment, Serbia, sustainable economic development

\section{Introduction}

The Sustainable Development Goals (SDGs) of the Agenda 2030 had been put into effect since the 1st of January 2016 and they are known as the global goals which, first and foremost, include fighting against poverty and inequality and tend to find a solution for the climate change problems. The 8th goal belongs to the first group of goals and it promotes an inclusive and sustainable economic growth, full and productive employment and decent work for everyone. Productive employment depends on the quality of the human capital, access to technology and innovations, regulative framework and macroeconomic stability. It refers to "all employment (for salaries or as self-employed) that provides sufficient income to enable the worker and his/her family/family members to 
obtain a material standard of living above the poverty line" (The International Labour Organization, 2012).

In order to maintain higher levels of economic productivity, working conditions are of huge importance. High employment must not be achieved at the expense of them, jeopardizing the human and labour rights of employees. Decent work should be attainable and available to all. The term was originally used by the International Labour Organization (ILO) in order to emphasize that quantity (level of employment) should not be achieved separately from quality. It refers to the opportunity to "obtain productive work in conditions of freedom, equity, security and dignity" (ILO, 1999). In order to achieve it, four interrelated objectives or pillars of decent work were defined: fostering employment, guaranteeing rights at work, extending social protection and promoting social dialogue. Since then, decent work has become general, worldwide goal, accepted by major regional integrations, global organizations and included in many human rights declarations and development strategies.

Serbia has been dedicated to the implementation of the Agenda 2030 and therefore the Government has been prioritizing and adapting the SDGs and targets to the national environment. Still, the country faces many difficulties on its journey to achieving a sustainable economic growth. Some of the key problems will be addressed in this paper and examined through chosen indicators of the $8^{\text {th }}$ sustainable development goal. Since Serbia is a candidate country for membership of the EU, its position will be analyzed among the neighboring countries which are member states (Bulgaria, Romania and Croatia), the leading EU states with highest GDP per capita (Luxembourg, Denmark and Netherlands) and compared to the EU average.

\section{Gender inequality at the labor market and long-term unemployment as problems of productive employment}

The main indicators of the existence of gender inequality are based on the differences between men and women at the job market. The majority of the unemployed people is consisted of women, both in the sense of work and experience and the time required for them to find a job. Besides that, the percentage of women in the typicallywoman professions is on the increase (Bošković \& Njegovan, pp. 115, 2012). Despite the fact that the situation at the job market in Serbia is not good for both the perspectives of men and women, women are still the ones who are hurt the most by the lower rate of employment. Despite characterized by the similar education levels, women are consistently recording lower employment rates in Serbia. They are also represented in the category of inactive population and unemployed people. Furthermore, a large number of unemployed women (12.5\%) has been actively searching for a job for a period longer than 10 years, which lowers their skills (Reva, pp. 2, 2012). 
Table 1. Employment Rate for Analyzed Countries* (\% of population aged 20 to 64).

\begin{tabular}{|c|c|c|c|c|c|c|c|c|c|}
\hline \multicolumn{10}{|c|}{ Year } \\
\hline Country & 2010 & 2011 & 2012 & 2013 & 2014 & 2015 & 2016 & 2017 & Average \\
\hline Serbia & - & - & - & - & 54.8 & 56.0 & 59.1 & 61.4 & 57.8 \\
\hline Bulgaria & 64.7 & 62.9 & 63.0 & 63.5 & 65.1 & 67.1 & 67.7 & 71.3 & 65.7 \\
\hline Romania & 64.8 & 63.8 & 64.8 & 64.7 & 65.7 & 66.0 & 66.3 & 68.8 & 65.6 \\
\hline Croatia & 62.1 & 59.8 & 58.1 & 57.2 & 59.2 & 60.6 & 61.4 & 63.6 & 60.2 \\
\hline EU28 & 68.6 & 68.6 & 68.4 & 68.4 & 69.2 & 70.1 & 71.1 & 72.2 & 69.6 \\
\hline Netherlands & 76.8 & 76.4 & 76.6 & 75.9 & 75.4 & 76.4 & 77.1 & 78.0 & 76.6 \\
\hline Denmark & 75.8 & 75.7 & 75.4 & 75.6 & 75.9 & 76.5 & 77.4 & 76.9 & 76.1 \\
\hline Luxembourg & 70.7 & 70.1 & 71.4 & 71.1 & 72.1 & 70.9 & 70.7 & 71.5 & 71.1 \\
\hline
\end{tabular}

*The data for Serbia are available from 2014.

If we take the total employment rates for the 8-year-long period (2010-2017) for Serbia, the chosen countries around Serbia (Bulgaria, Romania and Croatia), the average of EU28, the chosen countries members of the EU with the best indicators (as the criteria GDP per capita was taken during the period of 8 years) and the average of the 8-year-long period of those countries, we can conclude the following: Serbia had the worst position in all years analyzed in comparison with the neighboring countries, whereby her average employment rate for the 8-year-long period was closest to the average which Croatia achieved. The employment rate in Serbia has only topped $60 \%$ in 2017 . The employment rate average of the 8-year-long period on the EU28 level is close to $70 \%$, whereby the highest employment was achieved by the Netherlands at $78 \%$ in the past year (Eurostat). "Employed persons are defined as all persons who, during a reference week, worked at least one hour for pay or profit or were temporarily absent from such work" (Eurostat).

The following Table (Table 2) points out to the existence of the gender gap in employment in Serbia, as well as in the neighboring countries and the well-developed countries of the EU as well (Eurostat). The average employment rate for men in Serbia is for $14.7 \%$ greater than the same employment rate for women, which makes significant disparity, smaller only than the one Romania has (16.6\%). In comparison with the other analyzed countries, the gender gap in Serbia is greater than the one in the neighboring countries (Bulgaria - 6.7\%; Croatia - 10.4\%) as well as the average inequality of the whole EU $(12 \%)$, but also as the one in the Netherlands $(11.2 \%)$, Denmark $(6.6 \%)$ and Luxembourg $(13.2 \%)$. It is interesting to notice that the countries with the high average employment rates have significant differences between the employed men and women (the Netherlands and Luxembourg). On the other hand, from the countries neighboring Serbia, Bulgaria has a favorable position in terms of the difference between such rates. 
Table 2. Employment Rate by Sex for Analyzed Countries* (\% of population aged 20 to 64).

\begin{tabular}{|l|c|c|c|c|c|c|c|c|c|}
\hline \multicolumn{1}{|c|}{ Country } & 2010 & 2011 & 2012 & 2013 & 2014 & 2015 & 2016 & 2017 & Average \\
\cline { 2 - 10 } & $\mathrm{m} / \mathrm{f}^{\star *}$ & $\mathrm{~m} / \mathrm{f}$ & $\mathrm{m} / \mathrm{f}$ & $\mathrm{m} / \mathrm{f}$ & $\mathrm{m} / \mathrm{f}$ & $\mathrm{m} / \mathrm{f}$ & $\mathrm{m} / \mathrm{f}$ & $\mathrm{m} / \mathrm{f}$ & $\mathrm{m} / \mathrm{f}$ \\
\hline \multirow{2}{*}{ Serbia } & - & - & - & - & $62.4 /$ & $63.7 /$ & $66.3 /$ & $68.5 /$ & $65.2 /$ \\
& & & & & 47.2 & 48.4 & 51.9 & 54.5 & 50.5 \\
\hline \multirow{2}{*}{ Bulgaria } & $68.6 /$ & $66.0 /$ & $65.8 /$ & $66.4 /$ & $68.1 /$ & $70.4 /$ & $71.3 /$ & $75.3 /$ & $69.0 /$ \\
& 60.8 & 59.8 & 60.2 & 60.7 & 62.0 & 63.8 & 64.0 & 67.3 & 62.3 \\
\hline \multirow{2}{*}{ Romania } & $73.1 /$ & $71.5 /$ & $72.8 /$ & $72.8 /$ & $74.0 /$ & $74.7 /$ & $75.0 /$ & $77.3 /$ & $73.9 /$ \\
& 56.5 & 56.2 & 56.7 & 56.5 & 57.3 & 57.2 & 57.4 & 60.2 & 57.3 \\
\hline \multirow{2}{*}{ Croatia } & $67.9 /$ & $66.1 /$ & $63.7 /$ & $61.6 /$ & $64.2 /$ & $65.4 /$ & $66.2 /$ & $68.9 /$ & $65.5 /$ \\
& 56.4 & 53.6 & 52.6 & 52.8 & 54.2 & 55.9 & 56.6 & 58.3 & 55.1 \\
\hline \multirow{2}{*}{ EU28 } & $75.1 /$ & $75.0 /$ & $74.6 /$ & $74.3 /$ & $75.0 /$ & $75.9 /$ & $76.9 /$ & $78.0 /$ & $75.6 /$ \\
& 62.1 & 62.2 & 62.4 & 62.6 & 63.5 & 64.3 & 65.3 & 66.5 & 63.6 \\
\hline \multirow{2}{*}{ Netherlands } & $82.8 /$ & $82.4 /$ & $82.3 /$ & $81.1 /$ & $81.1 /$ & $81.9 /$ & $82.6 /$ & $83.3 /$ & $82.2 /$ \\
& 70.8 & 70.4 & 71.0 & 70.6 & 69.7 & 70.8 & 71.6 & 72.8 & 71.0 \\
\hline \multirow{2}{*}{ Denmark } & $78.6 /$ & $79.0 /$ & $78.6 /$ & $78.7 /$ & $79.5 /$ & $80.2 /$ & $80.7 /$ & $80.2 /$ & $79.4 /$ \\
& 73.0 & 72.4 & 72.2 & 72.4 & 72.2 & 72.6 & 74.0 & 73.7 & 72.8 \\
\hline \multirow{2}{*}{ Luxembourg } & $79.2 /$ & $78.1 /$ & $78.5 /$ & $78.0 /$ & $78.4 /$ & $76.7 /$ & $76.1 /$ & $75.4 /$ & $77.6 /$ \\
& 62.0 & 61.9 & 64.1 & 63.9 & 65.5 & 65.0 & 65.1 & 67.5 & 64.4 \\
\hline
\end{tabular}

${ }^{*}$ Employment rate by sex (m-male; f-female).

Figure 1 (Statistical Office of the Republic of Serbia, 2017) points out to the unemployment rate of men and women aged from 15 to 24 in the 2017 which was very high, as well as to the drastic disparity between the unemployment rate of men and women. This indicates the fact that young people are faced with the serious problem of unemployment in Serbia, whereby such rates are significantly lower for men if we compare the young aged from 15 to 24 , and the difference between men and women is considerably lower if we compare the people from 15 to 64, even though men are in a somewhat better position for this age structure as well. On the other hand, if we look the employment rates, men have a better position in the 15 to 24 age group as well as in the age group from 15 to 64 and these differences between women and men are significant for both age groups. The employment rate is significantly higher in the population of 15 to 64 years, for both women and men.

One of the indicators within the 8th goal of the Sustainable Development Goals is directly connected to the long-term unemployment rates. This indicator points to "the share of the economically active population aged 15 to 74 who has been unemployed for 12 months or more. Unemployed persons are defined as all persons who were without work during the reference week, were currently available for work and were either actively seeking work in the last four weeks or had already found a job to start within the next three months" (Eurostat).

Table 3 points out that Serbia has significantly lowered the long-term unemployment rate during the past few years, but also that her average rate is still by far the highest compared to all analyzed countries and it is more than twice bigger than the one within the countries of the EU28, whereby Croatia holds the second place (Eurostat). It is interesting that Romania recorded a long-term unemployment rate in the 8-year-long period which was lower than the EU average. Also, the Netherlands, Denmark and 
Luxembourg recorded rates which were significantly lower than the average rates of EU28 countries.

Figure 1. Employment Rate and Unemployment Rate for Females and Males in Serbia (2017).

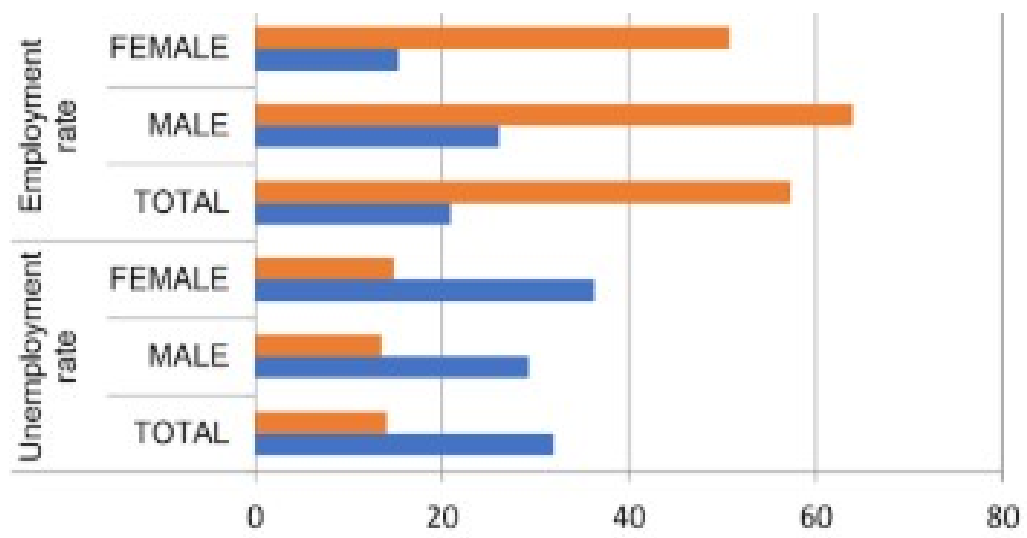

\section{" 2017 Population15-64}

= 2017 Youth 15-24

Table 3. Long-term Unemployment Rate for Analyzed Countries (\% of active population).

\begin{tabular}{|l|c|c|c|c|c|c|c|c|c|}
\hline \multicolumn{10}{|c|}{ Year } \\
\hline \multicolumn{1}{|c|}{ Country } & 2010 & 2011 & 2012 & 2013 & 2014 & 2015 & 2016 & 2017 & Average \\
\hline Serbia & - & - & - & - & 12.4 & 10.6 & 9.1 & 7.2 & 9.8 \\
\hline Bulgaria & 4.7 & 6.3 & 6.8 & 7.4 & 6.9 & 5.6 & 4.5 & 3.4 & 5.7 \\
\hline Romania & 2.4 & 2.9 & 3.0 & 3.2 & 2.8 & 3.0 & 3.0 & 2.0 & 2.8 \\
\hline Croatia & 6.6 & 8.4 & 10.2 & 11 & 10.1 & 10.2 & 6.6 & 4.6 & 8.5 \\
\hline EU28 & 3.8 & 4.1 & 4.6 & 5.1 & 5.0 & 4.5 & 4.0 & 3.4 & 4.3 \\
\hline Netherlands & 1.2 & 1.6 & 1.9 & 2.5 & 2.9 & 3.0 & 2.5 & 1.9 & 2.2 \\
\hline Denmark & 1.5 & 1.8 & 2.1 & 1.8 & 1.7 & 1.7 & 1.4 & 1.3 & 1.7 \\
\hline Luxembourg & 1.3 & 1.4 & 1.6 & 1.8 & 1.6 & 1.9 & 2.2 & 2.1 & 1.7 \\
\hline
\end{tabular}

If we compare such rates via genders, we can make a conclusion that is related to the differences which exist between men and women in the analyzed countries, when longterm unemployment is concerned (Eurostat). Serbia recorded a higher rate of long-term unemployment in every year that was analyzed, especially in terms of women being largely more unemployed than men, and that gap during the analyzed period was around $1.5 \%$. Such difference of the average rates was recorded by Bulgaria as well, even though the rates were several times lower in this case. Besides that, Bulgaria has recorded a significant decrease in the long-term unemployment for women in the analyzed period, 
thus the long-term unemployment for men was even higher than the one for women. It is interesting that Romania has had a higher average long-term unemployment rate for men compared to women during the period $(0.7 \%)$. Also, those average rates for men and women are equal at the level of the EU countries in the analyzed period. Alongside Bulgaria, in Denmark an average long-term unemployment rate of women has been lower than the one for men, even though such difference was considerably smaller $(0.1 \%)$ if compared with Romania for example. However, it can be noticed that such differences are minimal within other developed countries as well.

Table 4. Long-term Unemployment Rate for Analyzed Countries by Sex* (\% of active population).

\begin{tabular}{|l|c|c|c|c|c|c|c|c|c|}
\hline \multicolumn{1}{|c}{ Country } & 2010 & 2011 & 2012 & 2013 & 2014 & 2015 & 2016 & 2017 & Average \\
\cline { 2 - 10 } & $\mathrm{m} / \mathrm{f}^{\star *}$ & $\mathrm{~m} / \mathrm{f}$ & $\mathrm{m} / \mathrm{f}$ & $\mathrm{m} / \mathrm{f}$ & $\mathrm{m} / \mathrm{f}$ & $\mathrm{m} / \mathrm{f}$ & $\mathrm{m} / \mathrm{f}$ & $\mathrm{m} / \mathrm{f}$ & $\mathrm{m} / \mathrm{f}$ \\
\hline \multirow{2}{*}{ Serbia } & - & - & - & - & $\begin{array}{c}11.5 / \\
13.4\end{array}$ & $9.9 / 11.6$ & $8.6 / 9.8$ & $6.7 / 7.8$ & $9.2 / 10.7$ \\
\hline Bulgaria & $5.0 / 4.4$ & $7.0 / 5.5$ & $7.7 / 5.8$ & $8.1 / 6.6$ & $7.7 / 6.0$ & $6.1 / 5.0$ & $4.8 / 4.1$ & $3.6 / 3.2$ & $3.6 / 5.1$ \\
\hline Romania & $2.8 / 1.9$ & $3.2 / 2.6$ & $3.3 / 2.7$ & $3.4 / 3.0$ & $3.1 / 2.4$ & $3.3 / 2.6$ & $3.3 / 2.5$ & $2.4 / 1.5$ & $3.1 / 2.4$ \\
\hline Croatia & $5.9 / 7.3$ & $8.4 / 8.5$ & $\begin{array}{c}10.2 / \\
10.2\end{array}$ & $\begin{array}{c}11.3 / \\
10.6\end{array}$ & $\begin{array}{c}9.6 / \\
10.7\end{array}$ & $10.1 / 10.4$ & $6.8 / 6.5$ & $4.7 / 4.5$ & $8.4 / 8.6$ \\
\hline EU28 & $3.9 / 3.7$ & $4.1 / 4.1$ & $4.6 / 4.6$ & $5.1 / 5.1$ & $5.0 / 5.0$ & $4.5 / 4.5$ & $3.9 / 4.0$ & $3.3 / 3.5$ & $4.3 / 4.3$ \\
\hline Netherlands & $1.2 / 1.2$ & $1.6 / 1.7$ & $1.8 / 2.0$ & $2.6 / 2.5$ & $2.8 / 3.0$ & $3.0 / 2.9$ & $2.4 / 2.7$ & $1.8 / 2.1$ & $2.2 / 2.3$ \\
\hline Denmark & $1.8 / 1.1$ & $2.0 / 1.7$ & $2.1 / 2.1$ & $1.6 / 2.0$ & $1.7 / 1.7$ & $1.6 / 1.7$ & $1.3 / 1.4$ & $1.3 / 1.3$ & $1.7 / 1.6$ \\
\hline Luxembourg & $1.2 / 1.3$ & $1.3 / 1.6$ & $1.3 / 1.9$ & $1.6 / 1.9$ & $1.6 / 1.6$ & $1.9 / 1.9$ & $2.2 / 2.1$ & $2.3 / 1.9$ & $1.7 / 1.8$ \\
\hline
\end{tabular}

* Long-term unemployment rate by sex (m-male; f-female).

\section{Limiting factors of working environment in Serbia}

To eradicate the poverty, employment is considered as the best weapon. Therefore, creating more and better jobs is one of the main goals in each country. Unfortunately, being employed does not always provide satisfactory standard of living, especially in undeveloped and developing countries. Not only that work is essential as a means to provide income for food, housing, clothing, education and health care, it also gives opportunities to gain knowledge and skills, social connections and to integrate into the community (Gross, 2010; Frey \& MacNaughton, 2016). However, not all jobs have positive effects on person's development and well-being considering that incomes are often not enough to satisfy the basic needs, while many jobs are tedious and degrading, even dangerous. Furthermore, since employment is one of the major determinants of economic growth, governments often strive for high employment rates neglecting its quality. Serbia is a good example of such politics. In the past years, the government has been giving high subsidies and tax reliefs to encourage foreign investors to come and many factories have been opened. Although jobs have been created, and more people have got an opportunity to be employed, working conditions in many cases have been far 
from desired. Poor salaries, long working hours, bad social protection and violation of labour rights are some of the major difficulties Serbian employees deal with.

In the EU statistics, the in work at-risk-of-poverty rate measures the proportion of people who have an equivalised disposable income below the risk-of-poverty threshold, which is set at $60 \%$ of the national median equivalised disposable income (after social transfers), while being employed. A person is considered as an employee if he/she has been employed for more than half of the reference year. The Eurostat data (Table 5) implies that risk of poverty among working population could be high even in developed countries. Despite the fact that Luxembourg has the highest GDP per capita in Europe, its risk of poverty is higher than the EU average. Romania is the EU member state with the worst ranking regarding this indicator, having the rate twice as high as the EU average. Serbia is not in the enviable position either. According to the Eurostat, the in work at-riskof-poverty rate in Serbia has been around 13\% in the $2013-2017$ period, which is about 4\% higher than the EU average. The Survey on Income and living conditions, conducted in 2017 showed that $10.8 \%$ of persons who work were at the risk of poverty. The rate was much higher among self-employed (agricultural workers are involved) - around 35\%, than among employees $-6.8 \%$ (Statistical Office of the Republic of Serbia, 2018).

Table 5. In work at-risk-of-poverty rate ( $\%$ of employed persons aged 18 or over).

\begin{tabular}{|l|c|c|c|c|c|c|c|c|c|}
\hline \multicolumn{1}{|c|}{ Country } & 2010 & 2011 & 2012 & 2013 & 2014 & 2015 & 2016 & 2017 & Average \\
\hline Serbia & - & - & - & 14.9 & 14 & 13.3 & 11.9 & 10.8 & 13 \\
\hline Bulgaria & 7.7 & 8.2 & 7.4 & 7.2 & 9.2 & 7.7 & 11.4 & 9.9 & 8.6 \\
\hline Romania & 17.9 & 19.1 & 19 & 18.4 & 19.8 & 18.8 & 18.9 & 17.4 & 18.7 \\
\hline Croatia & 6.3 & 6.6 & 6 & 6.2 & 5.7 & 5.9 & 5.6 & 5.8 & 6 \\
\hline EU 28 & 8.3 & 8.8 & 8.9 & 9 & 9.5 & 9.5 & 9.6 & 9.4 & 9.1 \\
\hline Netherlands & 5.1 & 5.4 & 4.6 & 4.5 & 5.3 & 5 & 5.6 & 6.1 & 5.2 \\
\hline Denmark & 6.5 & 6.3 & 5.2 & 5.5 & 4.9 & 5.5 & 5.3 & 5.3 & 5.6 \\
\hline Luxembourg & 10.6 & 9.9 & 10.2 & 11.2 & 11.1 & 11.6 & 12 & 13.7 & 11.3 \\
\hline
\end{tabular}

Eurostat data also indicate that Serbia is among countries with lowest minimum wage in Europe although it has increased in the last few years, from around 232 euros/month in 2014 to 285 euros/month in 2018. Considering that minimal consumer basket value was about 300 euros in December 2018, it is obvious that minimum wage is not enough even for the basic needs. Furthermore, the official data from Ministry of Trade, Tourism and Telecommunications show that in December 2018, the average consumer basket required more than one average net salary, precisely 1,35 (Ministry of Trade, Tourism and Telecommunications, 2019).

Besides working poverty and high unemployment among young people, additional problem in many countries is high share of youth who are not in employment, education or training. Without certain level of education and skills, their possibilities of employment in the future are significantly reduced, which, furthermore, slows down the economy growth in 
the long run. Promoting learning, training and education among youth is one of the key factors for achieving economic progress which will be sustained over the longer period of time. Especially in today's era of knowledge driven development, where innovation and knowledge are considered crucial. Therefore, the share of young people neither in employment, nor in education and training is a good indicator of country's limitation and potential for sustainable economic development in the future. It shows the share of young people, 15 to 29 years old, who are not involved in education or training, nor employed. In the EU statistics the numerator of the indicator includes those who fulfill the following criteria: they are not employed (unemployed or inactive) and they have not been enrolled in any educational institution or training course for at least four weeks prior to the conducted survey. The denominator presents the total population aged 15 to 29 (excluding those who did not participate in the survey). According to the data provided by Eurostat (Table 6), the position of Serbia is pretty alarming regarding this category. Besides evident lagging behind developed countries, as well as the EU average, Serbia is at the very bottom of the list, with the percentage of youth not in employment, education and training higher than any EU country, even the least developed.

Table 6. Young people neither in employment nor in education and training (\% of population aged 15 to 29$)$.

\begin{tabular}{|c|c|c|c|c|c|c|c|c|c|}
\hline \multicolumn{10}{|c|}{ Year } \\
\hline Country & 2010 & 2011 & 2012 & 2013 & 2014 & 2015 & 2016 & 2017 & Average \\
\hline Serbia & 24.8 & 26.2 & 26.2 & 25.5 & 25.5 & 24.6 & 22.3 & 21.7 & 24.6 \\
\hline Bulgaria & 23.5 & 24.7 & 24.7 & 25.7 & 24 & 22.2 & 22.4 & 18.9 & 23.3 \\
\hline Romania & 18.9 & 19.5 & 19.3 & 19.6 & 19.9 & 20.9 & 20.2 & 17.8 & 19.5 \\
\hline Croatia & 17.6 & 19.1 & 19.7 & 22.3 & 21.8 & 19.9 & 19.5 & 17.9 & 19.7 \\
\hline EU 28 & 15.2 & 15.4 & 15.9 & 15.9 & 15.3 & 14.8 & 14.2 & 13.4 & 15 \\
\hline Netherlands & 5.7 & 5.9 & 6.5 & 7.5 & 7.6 & 6.7 & 6.3 & 5.9 & 6.5 \\
\hline Denmark & 7.3 & 7.6 & 8.2 & 7.5 & 7.3 & 7.7 & 7.4 & 9.1 & 7.7 \\
\hline Luxembourg & 6.1 & 6.6 & 7.6 & 7.2 & 6.5 & 7.6 & 6.8 & 6.6 & 6.9 \\
\hline
\end{tabular}

Not completing secondary or tertiary level of education and not gaining skills through training limits opportunities for employment, but also increases the risk of poverty among the youth and later in life. According to the Statistical Office of the Republic of Serbia, poverty rate of unemployed in Serbia is about $50 \%$, which is considerably higher than among those who work, and than the overall at-risk-of poverty rate $-25.7 \%$, as well as at-risk-of-poverty or social exclusion rate $-36.7 \%$. Furthermore, the Survey on Income and living conditions points out that currently most vulnerable aged groups in Serbia, in terms of poverty, are young people, even $30.5 \%$ of them up to 17 years of age and $29.7 \%$ aged 18-24 (Statistical Office of the Republic of Serbia, 2018).

Another significant problem in Serbia, which influences the business environment, is high share of informal economy. In late 2017, the National Alliance for Local Economic Development (NALED), with the support of German Development Cooperation, produced the study on shadow economy in order to identify the extent of informal economy, 
characteristics of its participants, as well as the key factors. The results showed that the scope of grey economy has been reduced, from $21.2 \%$ of GDP in 2012 to $15.4 \%$ of GDP in 2017, while using the new survey method (which is based on the data about nonregistered salaries and non-declared profit) estimations were slightly better $-14.9 \%$ of GDP (Krstić \& Radulović, 2018). Since the study included registered business entities only, just a segment of informal economy was analyzed, implying that the real situation is certainly worse. The research indicated that dominant form of informal economy in Serbia is unregistering employees and that much larger share of grey economy is related to payment of salaries in cash than to non-declared profit. In 2017, $16.9 \%$ of registered business was involved in some sort of informal activities, out of which $10.8 \%$ had unregistered workers, $6.9 \%$ was paying salaries in cash, although they were VAT (value added tax) taxpayers, while slightly less than $1 \%$ of companies had been engaged in both forms of informal economy. When the estimated share of enterprises that are unregistered $(17.2 \%)$, according to the owners/managers' opinion, is added to that, the results imply that one third of business entities in Serbia operates within the grey zone. Such circumstances lead to unfavorable working conditions. Working as an unregistered employee leaves the individual without social and health insurance and totally deprived of labour rights. There are usually no guarantee that the wage will be received, or at least on time, working hours might be longer than normal, without the extra pay, and the sick leave is often a reason for dismissal. All of that raises the dissatisfaction of workers and their concerns about job security and has negative impact on their motivation and productivity.

Such trends and labour market conditions have led to massive "brain drain", a trend which has been presented in Serbia for years and has reached enormous proportions lately. Projections for the future are even more disturbing. In a recently published extensive research by Gallup, the US analytical-research center, conducted among nearly half a million adults from 152 countries around the world between 2015 and 2017, the Potential Net Migration Index for Serbia has negative values (Gallup, 2017). The results show that around $25 \%$ of adult population in Serbia might leave the country in the next few years. The expectations are even worse regarding the young population aged 15 to 29 , since almost half of them $(46 \%)$ is thinking about leaving forever. Among highly educated residents, with bachelor's degree or higher, $27 \%$ of them is considering moving abroad. Some estimates of the Organization for Economic Cooperation and Development (OECD) suggest that Serbia could lose around 9 billion $\$$ as a direct consequence of brain drain in the science, technology, and innovation sectors (Vracic, 2018).

\section{Encouraging productive employment - strategies and programs}

For fulfilling the goal of productive employment and decent work, a development of certain mechanisms for strengthening the competitiveness of economy is needed; through development of innovations, entrepreneurship and sectors of small and medium enterprises, improving the quality of the educational system, implementation of measures for encouraging youth employment, especially younger women. In this regard, a key part is played by certain strategies and programs which the country uses to encourage a sustainable and stable growth. 
An important basis for fulfilling the goals of productive employment and decent work includes the Strategy of Scientific and Technological Development of the Republic of Serbia for the 2016-2020 period - Research and Innovation (Official Gazette RS, 2016). It highlights the importance of science, innovation and technological advancement for the social and economic development of the country, with a goal of developing innovations, and it predicts a more efficient method of managing the system of innovations in Serbia. It especially highlights the importance of larger investments in research and growth, as well as for the private sector and the state sector.

The basic goal of the National Employment Strategy for the 2011-2020 period is a stable and sustainable trend of employment growth and reduction in disparities of the EU and Serbia labor market indicators. It also points out to the importance of the development of human resources via the increase of the workforce quality and social engagement of individuals and groups. The strategic goal would be not only to increase the number of job offers in the private sector, but also to increase the quality of the workplaces, and it particularly should encourage employment in the less-developed regions of Serbia. The sector of small and medium enterprises is recognized as the bearer of the sustainable growth. This strategy includes the especially vulnerable groups on the job market in Serbia, among which are women and the young from 15 to 24 years of age (Official Gazette RS, 2011).

The problem of youth employment was also considered within the National Youth Strategy for the 2015-2025 period. Its basic goal was the employment and entrepreneurship of the youth, having in mind that the largest unemployment rate in Serbia is present within the population from 15 to 24 years of age, and besides that, it is the age group in which the largest difference between the employment of men and women was recorded (Official Gazette RS, 2015). It predicts some of the following measures: offering support for the programs that encourage the young to apply for the National Program of Professional Practice, offering professional and working practice with financial compensation, development of the mechanisms for conducting the internships and other forms of acquisition of work experience during schooling, development of the models for investments done by the private sector in the entrepreneurship of the young, establishment of the mechanisms for the financial support of the young in their early entrepreneurship steps, development of the support programs for young women who decide to self-employ in the traditionally male-oriented business sectors, creation of the all-inclusive programs for career guidance and advising the young. The end goal of such measures is the development of competence and innovation within the young, which would benefit the employment of young men and women. Researches (Marjanović, 2016) show that young women remain longer in the education system than men do. The percentage of the young men and women who have completed their primary education is approximate $(16.1 \%$ for women and $16.6 \%$ for men), but there is a considerably larger number of women who have completed their third-degree education than men (30.9\% women and $17.4 \%$ men). However, this has not enabled women to attain a better position at the job market.

The Strategy for Education Development in Serbia should improve the quality of the education system in Serbia until 2020, maintaining and monitoring certain quality standards on the level of the educational institutions and programs, but also to increase 
the availability of the educational institutions for socially-sensitive groupings in Serbia. Such strategy recognizes that the organized and quality-based development of the education system in Serbia is of crucial importance for the development of the knowledgebased society which should provide the population with decent jobs. Such strategy leans toward the development of the economy based on knowledge while maintaining the living environment, promotion of entrepreneurship among the educated population, technological advancements, market economy and international business, technical and other cooperation (Official Gazette RS, 2012).

The Strategy for Support for the Development of Small and Medium-sized Enterprises, Entrepreneurship and Competitiveness for the 2015-2020 period is directed towards the development of micro, small and medium-sized enterprises, private entrepreneurship initiatives, innovations and usage of new technologies (Official Gazette RS, 2015). This way, the Strategy contributes to the realization of the 8th goal of the Agenda 2030, aiming to encourage a long-term competitiveness of small and mediumsized enterprises in Serbia, which considerably boost competitiveness of the national economy. The small and medium-sized enterprises sector is the crucial support for the Serbian economy (Ivković, Čukanović-Karavidić, Vujičić, 2012). However, such enterprises in Serbia are faced with the problem of lacking the initial capital and insufficient knowledge of the market needs.

Economic Reform Programme for the Period 2018-2020 emphasizes certain structural reforms that contribute to the goal of productive employment. These reforms relate to: reduction of the informal economy, research, development and innovation and digital economy, education and skills, employment and labour market, social inclusion, poverty reduction and equal opportunities (Government of the Republic of Serbia, 2018). The Reform Program of Employment and Social Policy in the EU Accession Process (ESRP) was adopted in May 2016 and contains key reforms in the area of employment and labour market, human capital and skills, social inclusion and protection, and unemployment of the youth as a vulnerable category.

In order to stop the exodus of young people, in January 2019 the Government formed a team of experts, ministers, professors and employees' representatives. Their main task is to monitor migration of the young, analyze causes of leaving the country and develop strategies to prevent it. The team is expected to create short-term and long-term plans and implement measures necessary to improve the living and working conditions for young people in Serbia.

The aforementioned Strategies play an important part of alleviating the barriers for the development of the productive employment and decent work in Serbia. Besides that, an important role is also played by: macroeconomic, industrial and market policy, which determine the conditions and basis for economic activity and growth; education policy which makes qualified workers and health policy which secures a productive workforce; financial policy; market policy, which enables fair and safe working conditions and respects the rights of the workers (Johansson de Silva \& Söderbäck, 2013). 


\section{Conclusion}

In order to achieve high and sustainable economic development, social and working conditions must be among top priorities. Men and women should have equal rights, including persons with disabilities, young people should be given chances for proper education, training and employment, all forms of forced labour should be completely eliminated, while work needs to be safe and secure for all. Economic progress in the long run cannot be maintained without well-paid quality jobs, labour rights protection and working environment which would promote decent work and create training and learning opportunities for the youth.

Serbia is facing many problems on its way to higher economic development. Its position in terms of employment, gender equality at the labour market, poverty rate and working conditions is still far from desired, usually at the very bottom of the Europe. The unemployment is high, especially among the young people, wages are below european standards, disparities in evaluation of equal work is present and the risk of poverty and social exclusion is serious. Such circumstances have led to rising number of people leaving the country that has reached huge proportions. In order to improve the economic environment and to prevent the further departure of young, highly educated population, it is necessary to increase incentives for entrepreneurs, investments in science and education, to encourage small and medium enterprises and to promote innovation. Education system should be enhanced, as well as opportunities for learning, gaining skills and training, which would make young people more competitive and professionally successful, and contribute to the competitiveness of national economy as well. Furthermore, creating high paid and high quality jobs should be of prime concern. In order to decrease unemployment, the quality of jobs and working conditions must not be neglected. Securing a safe working environment, protecting the rights of the workers and providing higher salaries, along with reduction of the informal economy, are fundamental for further development.

\section{References}

Bošković, O., Njegovan, N., (2012), Gender inequality in the Serbian Labour Market, Economic Annals, Vol. LVII, no. 192, pp. 113-135.

Frey, D., MacNaughton, G., (2016), A Human Rights Lens on Full Employment and Decent Work in the 2030 Sustainable Development Agenda, Journal of Workplace Rights, April-June 2016, pp. 1-13.

Gallup, (2017), Potential net migration index, available online at http://news.gallup.com/migration/interactive.aspx?g_source=link_newsv9\&g_campaign=ite m 245204\&g medium=copy

Government of Republic of Serbia, (2018), Economic Reform Programme for the Period 2018-2020.

Gross, J. A., (2010), A shameful business: The case for human rights in the American workplace, Cornell University Press.

International Labour Organization, (1999), Decent work: Report of the Director - General, International Labour Conference (87 $7^{\text {th }}$ Session), Geneva, Switzerland, ILO.

Ivić, I., Pesikan, A., (2012), Education system reforms in an unstable political situation: the case of Serbia in the first decade of the 21st century, CEPS Journal, Vol. 2, no. 2, pp. 31-53. 
Ivković, D., Čukanović-Karavidić, M., Vujičić, S., (2012), Small and Medium-Sized Enterprises as a Factor of Serbian Economy, Economic Analysis, Vol. 45, no. 3-4, pp. 31-45.

Johansson de Silva, S., Söderbäck, M., (2013), Study on Existing Models for Productive Employment and Possible Models for Funding, International Swedish Institute for Public Administration, SIPU.

Krstić, G, Radulović, B., (2018), Shadow economy in Serbia in 2017: the estimation of the scope, participants' characteristics and determinants, National Alliance for Local Economic Development, Belgrade.

Marjanović, D., (2016), Tranzicija mladih žena i muškaraca na tržištu rada Republike Srbije. Publikacija Work4Youth, Serija br. 36, Ženeva.

Ministry of Trade, Tourism and Telecommunications, (2019), Purchasing power of the population, consumer basket, December 2018, Ministry of Trade, Tourism and Telecommunications, Republic of Serbia.

Official Gazette RS, (2011), National Employment Strategy for the period 2011 - 2020, Official Gazette RS no. 37/2011.

Official Gazette RS, (2012), Strategy for Education Development in Serbia until 2020, Official Gazette RS no. 107/2012.

Official Gazette RS, (2015), National Youth Strategy for the period 2015 - 2025, Official Gazette RS no. $22 / 2015$.

Official Gazette RS, (2015), Strategy for Support to the Development of Small and Mediumsized Enterprises, Entrepreneurship and Competitiveness for the period of 2015-2020, Official Gazette RS no. 35/2015.

Official Gazette RS, (2016), Strategy of Scientific and Technological Development of the Republic of Serbia for the period from 2016 to 2020 - research for innovation, Official Gazette RS no. 25/2016.

Reva, A., (2012), Gender Inequality in the Labor Market in Serbia, Policy Research Working Paper 6008, The World Bank.

Statistical Office of the Republic of Serbia, (2018), Poverty and Social Inequality, 2017, Statistical release PD10, Number 345 - Year LXVIII, 25/12/2018, Republic of Serbia.

The International Labour Organization, (2012), Understanding deficits of productive employment and setting targets: a methodological guide, International Labor Office.

Vracic, A., (2018), The Way Back: Brain Drain and Prosperity in the Western Balkans - ECFR/257, Policy Brief, European Council on Foreign Relations, London. 